\title{
Reactions of difunctional electrophiles with functionalized aryllithium compounds: remarkable chemoselectivity by flash chemistry.
}

\section{AUTHOR(S):}

Nagaki, Aiichiro; Imai, Keita; Ishiuchi, Satoshi; Yoshida, Jun-ichi

\section{CITATION:}

Nagaki, Aiichiro ...[et al]. Reactions of difunctional electrophiles with functionalized aryllithium compounds: remarkable chemoselectivity by flash chemistry.. Angewandte Chemie 2014, 54(6): 1914-1918

\section{ISSUE DATE:}

2014-12-12

URL:

http://hdl.handle.net/2433/199605

\section{RIGHT:}

This is the peer reviewed version of the following article: Nagaki, A. Imai, K., Ishiuchi, S. and Yoshida, J.-i. (2015),

Reactions of Difunctional Electrophiles with Functionalized Aryllithium Compounds: Remarkable Chemoselectivity by Flash Chemistry. Angew. Chem. Int. Ed., 54: 1914-1918, which has been published in final form at

http://dx.doi.org/10.1002/anie.201410717:; 許諾条件により本文ファイルは2015-12-12に公開.; この論文は出版社版て ありません。引用の際には出版社版をご硨認じ利用ください。;This is not the published version. Please cite only the published version. 


\section{Benzyllithiums Bearing Aldehyde Carbonyl Groups. A Flash Chemistry Approach**}

\section{Aiichiro Nagaki, Yuta Tsuchihashi, Suguru Haraki, and Jun-ichi Yoshida*}

Chemoselectivity is one of the central issues in chemistry and chemical synthesis. ${ }^{[1]}$ One of the goals in synthetic chemistry is the development of chemoselective transformations without affecting highly reactive functional groups that are not involved in the desired transformation. We have been interested in organolithium reactions without affective aldehyde carbonyl groups as an extreme case of chemoselective transformations. ${ }^{[2]}$ According to textbooks of organic chemistry, organolithiums react with aldehyde very quickly and they are not compatible with each other. On the other hand, aldehyde carbonyl groups are very common functional groups and organolithium reactions are frequently used in organic synthesis. ${ }^{[3]}$ Therefore, if we could perform organolithium reactions without affecting aldehyde carbonyl groups, such reactions would serve as powerful synthetic methods. We took an approach to this challenge based on flash chemistry, ${ }^{[4]}$ in which a highly unstable reactive species are generated and transferred to another location to be used in the next reaction ${ }^{[5]}$ before they decompose by high-resolution residence time control using flow microreactor systems. ${ }^{[6-8]}$ Here, we show that flash chemistry enables the generation of benzyllithiums bearing aldehyde carbonyl groups and their use in the reactions with subsequently added electrophiles without affecting the aldehyde carbonyl groups.

Recently, we have reported the generation and reactions of aryllithiums bearing ketone carbonyl groups. ${ }^{[5 e]}$ Because aldehyde carbonyl groups are more reactive than ketone carbonyl groups in general, we envisaged that faster generation is necessary to solve the more challenging problem of aldehyde cases. Therefore, we chose to use reductive lithiation of benzyl halides instead of halogen/lithium exchange of aryl halides. ${ }^{[3,9]}$

Thus, we focused on the generation of benzyllithiums ${ }^{[10]}$ bearing aldehyde carbonyl groups by reductive lithiation of benzyl halides (Figure 1). ${ }^{[11]}$ In addition to functional group compatibility, there is another problem, i.e. Wurtz-type coupling, the coupling of benzyllithiums with starting benzyl halides. ${ }^{[12]}$ We envisioned that extremely fast micromixing is effective to avoid undesired Wurtztype coupling because it is known that the product selectivity of fast consecutive competitive reactions ${ }^{[13]}$ can be improved by extremely fast micromixing. ${ }^{[14]}$

At first, we examined the generation of simple benzyllithium. It was reported that benzyllithium can be generated from benzyl chloride by using lithium naphthalenide (LiNp) in a mixed solvent $\left(\mathrm{Et}_{2} \mathrm{O} / \mathrm{THF} /\right.$ light petroleum $\left.=4: 3: 1\right)$ at $-95^{\circ} \mathrm{C}$ in a conventional batch reactor. ${ }^{[11 a]}$ However, the reaction in THF and/or at higher

[*] Dr. A. Nagaki, Y. Tsuchihashi, S. Haraki, and Prof. J. Yoshida Department of Synthetic and Biologycal Chemistry,

Graduate School of Engineering, Kyoto University

Nishikyo-ku, Kyoto, 615-8510 (Japan)

Fax: (+81)75-383-2727

E-mail: yoshida@sbchem.kyoto-u.ac.jp

http://www.sbchem.kyoto-u.ac.jp/yoshida-lab/index e.htm

[**]This work was partially supported by the Grant-in-Aid for Scientific Research (S) (no. 26220804) and Scientific Research (B) (no. 26288049). temperatures such as $-78{ }^{\circ} \mathrm{C}$ leads to a dramatic decrease in the yield because of Wurtz-type coupling. The use of benzyl bromide also leads to Wurtz-type coupling. Keeping such backgrounds in mind, we examined the reactions of benzyl halides with LiNp in a flow microreactor system, which consists of two T-shaped micromixers (M1 $(\phi=250 \mu \mathrm{m})$ and $\mathbf{M} 2(\phi=250 \mu \mathrm{m}))$ and two microtube reactors $(\mathbf{R} 1(\phi=1000 \mu \mathrm{m}$, length $=3.5 \mathrm{~cm})$ and $\mathbf{R} \mathbf{2}(\phi=1000 \mu \mathrm{m}$, length $=50 \mathrm{~cm})$ ) shown in Figure 2. For the reactions with very short residence times such as $1.3 \mathrm{~ms}(\mathbf{R} 1(\phi=250 \mu \mathrm{m}$, length $=1.0$ $\mathrm{cm})$ ), a built-in type system (Figure 2a) was used, whereas a conventional modular type system was used for the reactions with longer residence times, (Figure 2b).

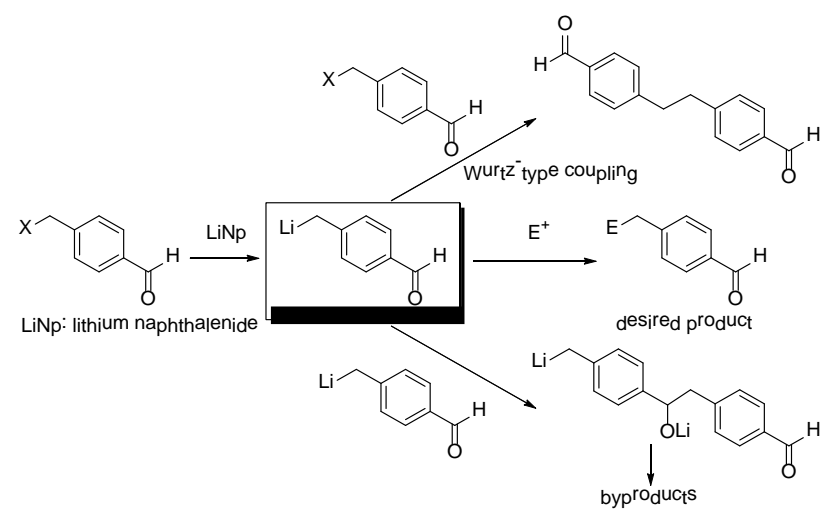

Figure 1. Generation and reactions of benzyllithiums bearing aldehyde carbonyl groups

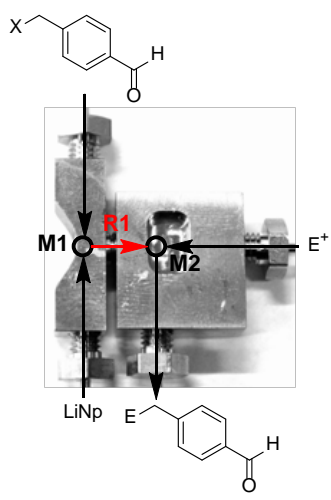

(a) (b)

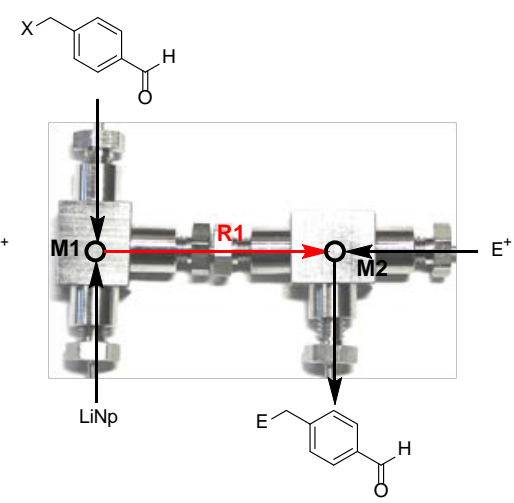

Figure 2. Flow microreactor systems. (a) built-in type system, (b) modular type system

Because it is well known that the mixing speed in a micromixer depends on the inner diameter and the flow rate, ${ }^{[15]}$ we examined the reactions with varying the inner diameter of M1 and the flow rates of the solution of benzyl halide and that of LiNp. The 1:1 molar ratio of benzyl halide and LiNp was kept in all experiments. Methanol was used as an electrophile and the reactions were carried out at $20^{\circ} \mathrm{C}$ using a conventional modular type system (Figure 2b). As summarized in Table 1, the yield of the desired protonated product, toluene increases with a decrease in the inner diameter. The yield also increases with an increase in the flow rate. Satisfactory yields were obtained with $\mathbf{M 1}$ of $250 \mu \mathrm{m}$ inner diameter and the total flow rate of $9.0 \mathrm{~mL} / \mathrm{min}$ for the case of benzyl chloride. In the case of benzyl bromide higher flow rate was necessary to obtain satisfactory yields, presumably benzyl bromide is more reactive toward benzyllithium than benzyl chloride. Anyway, it is noteworthy that the flow microreactor system enables the generation 
of benzyllithium at $20^{\circ} \mathrm{C}$, although the reactions should be carried out at $-95{ }^{\circ} \mathrm{C}$ in a conventional batch macro reactors. It is also advantageous that THF can be used instead of the mixed solvent. Furthermore, benzyl bromide can be used as a starting material, although such transformation is impossible in a conventional batch macro reactor. These remarkable features seem to be ascribed to extremely fast 1:1 (molar ratio) mixing in the micromixer.

Table 1. Effect of the flow rate and the inner diameter of M1 on the lithiation of benzyl halides using the flow microreactor system. ${ }^{[a]}$

\begin{tabular}{|c|c|c|c|c|c|c|}
\hline \multirow[t]{2}{*}{$X$} & \multicolumn{3}{|c|}{ flow rate $[\mathrm{mL} / \mathrm{min}]$} & \multirow{2}{*}{$\begin{array}{c}\text { inner diameter } \\
\text { of } \mathbf{M} \mathbf{1}[\mu \mathrm{m}]\end{array}$} & \multicolumn{2}{|c|}{ yield $[\%]^{[b]}$} \\
\hline & benzyl halide & LiNp & total & & toluene & bibenzyl \\
\hline \multirow[t]{3}{*}{$\mathrm{Cl}$} & 6.0 & 3.0 & 9.0 & 500 & 70 & 13 \\
\hline & 6.0 & 3.0 & 9.0 & 250 & 89 & 4 \\
\hline & 3.0 & 1.5 & 4.5 & 250 & 81 & 4 \\
\hline \multirow[t]{6}{*}{$\mathrm{Br}$} & 6.0 & 3.0 & 9.0 & 800 & 15 & 29 \\
\hline & 6.0 & 3.0 & 9.0 & 500 & 38 & 30 \\
\hline & 6.0 & 3.0 & 9.0 & 250 & 77 & 10 \\
\hline & 12 & 6.0 & 18 & 250 & 80 & 8 \\
\hline & 3.0 & 1.5 & 4.5 & 250 & 49 & 24 \\
\hline & 1.5 & 0.75 & 2.25 & 250 & 39 & 30 \\
\hline
\end{tabular}

[a] R1: $\phi=250 \mu \mathrm{m}, \mathrm{L}=3.5 \mathrm{~cm}, 20^{\circ} \mathrm{C}$. [b] Determined by GC using an internal standard.

Under the optimized conditions, the reactions of benzyllithium with other electrophiles, such as methyl iodide, aldehydes, ketones, trimethylsilyl chloride, and isocyanates were examined. As shown in Table 2, the corresponding products were obtained in good yields. Notably, the lithiation of 2-(chloromethyl)thiophene followed by the reaction with an electrophile was successfully achieved, although conventional batch reactions often suffer from the ring-opening side reaction. ${ }^{[16]}$

Table 2. The generation of benzyllithiums followed by reaction with an electrophile. [a]

(l)

[a] R1: $\phi=250 \mu \mathrm{m}, \mathrm{L}=3.5 \mathrm{~cm}, 20^{\circ} \mathrm{C}$. Benzyl chloride: total flow rate $=9 \mathrm{ml} / \mathrm{min}$. Benzyl bromide, 2-(chloromethyl)thiophene: flow rate of benzyl halide $=18 \mathrm{ml} / \mathrm{min}$. [b] Determined by GC using an internal standard. [c] Isolated yield.

With successful generation of benzyllithiums by virtue of extremely fast micromixing in hand, we next examined the generation and reactions of benzyllithiums bearing carbonyl groups. In this case the high-resolution residence time control should be critical because such benzyllithiums should be transferred extremely quickly to another location to be used in the reaction with electrophiles before they decompose. Temperature-residence time mapping serves as a powerful tool for optimizing the residence time. Figure 3a shows the contour plots with scattered overlay of the yields of the protonated product for the lithiation of $p$ propanoylbenzyl chloride, which has a ketone carbonyl group, followed by trapping with methanol. The yield decreases with an increase in the residence time in R1. The yield also decreases with an increase in the temperature although the effect of the temperature is not large. The optimal yield (80\%) was obtained with the residence time of $1.3 \mathrm{~ms}$ at $-78^{\circ} \mathrm{C}$.

(a)

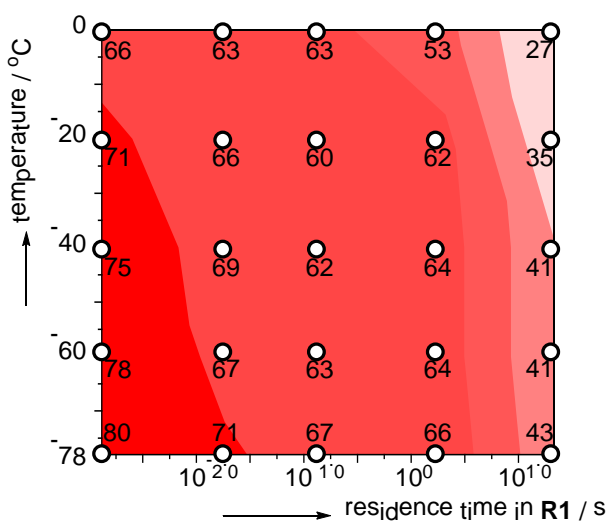

(b)

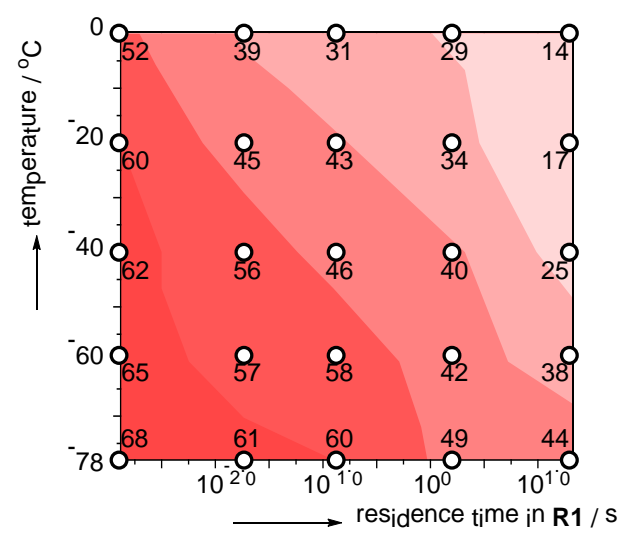

Figure 3. Effects of the temperature and the residence time in R1 on the yield of the protonated product for the lithiation of (a) p-propanoylbenzyl chloride and (b) $p$ formylbenzyl chloride with LiNp followed by trapping with methanol using the flow microreactor system. Contour plots with scattered overlay of the yields of the protonated products, which are indicated by numbered circles.

The effects of the residence time and the temperature are more significant in the lithiation of $p$-formylbenzyl chloride, which has an aldehyde carbonyl group (Figure 3b). As it can be seen obviously by comparing Figs $3 \mathrm{a}$ and $3 \mathrm{~b}, p$-formylbenzyllithium is significantly more unstable than $p$-propanoylbenzyllithium. With the residence time of $1.3 \mathrm{~ms}$ at $-78{ }^{\circ} \mathrm{C}$, however, $p$-formylbenzyllithium can be generated and used in the subsequent reaction with methanol to give the protonated product in a reasonable yield (68\%). This means that 
the aldehyde carbonyl group can survive in the organolithium reaction.

Table 3. The generation of benzyllithiums bearing ketone and aldehyde carbonyl groups followed by reaction with an electrophile. ${ }^{[a]}$

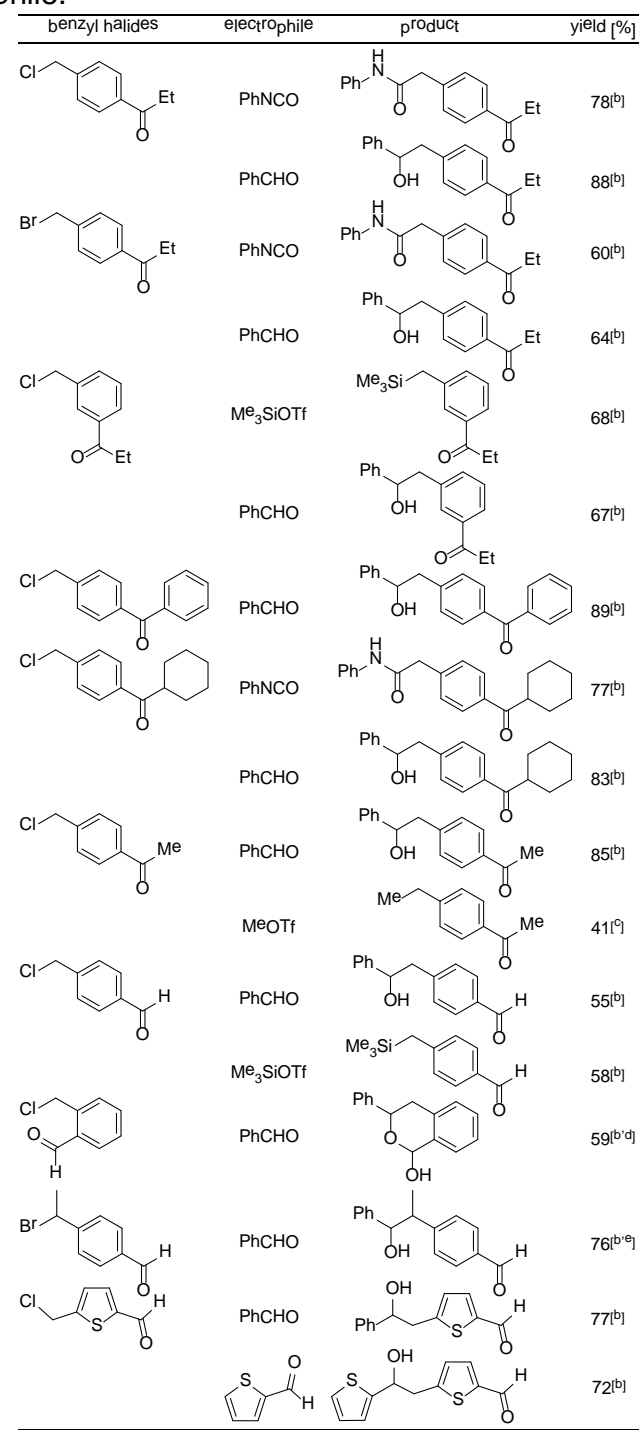

[a] R1: $\phi=250 \mu \mathrm{m}, \mathrm{L}=1.0 \mathrm{~cm},-78{ }^{\circ} \mathrm{C}$. [b] Isolated yield. [c] Determined by GC. [d] Diastereomeric ratio $=88: 12$ (determined by ${ }^{1} \mathrm{H}$ NMR). [e] Diastereomeric ratio $=60: 40$ (determined by ${ }^{1} \mathrm{H}$ NMR).

Under the optimized conditions several benzyllithiums bearing ketone and aldehyde carbonyl groups were generated and reacted with several electrophiles including phenylisocyanate, benzaldehyde, TMSOTf, and MeOTf. The results are summarized in Table 3. Such transformations are very difficult or practically impossible by using conventional batch macro reactors.

As an application of the present method, we accomplished the synthesis of a $\pi$-conjugated system shown in Figure 4 . The reaction of benzaldehyde with (5-formylthiophen-2yl)methyllithium followed by the elimination with $\operatorname{bis}[\alpha, \alpha-$ bis(trifluoromethyl)benzenemethanolato]diphenylsulfur (Martin sulfurane) gave aldehyde $\mathbf{1}$ in $61 \%$ isolated yield. The aldehyde carbonyl group in $\mathbf{1}$ was used for the subsequent reaction with benzyllithium. The subsequent dehydration gave compound 2 (78\% isolated yield), in which one thiophene ring and two benzene rings are connected by carbon-carbon double bonds. ${ }^{[17]}$

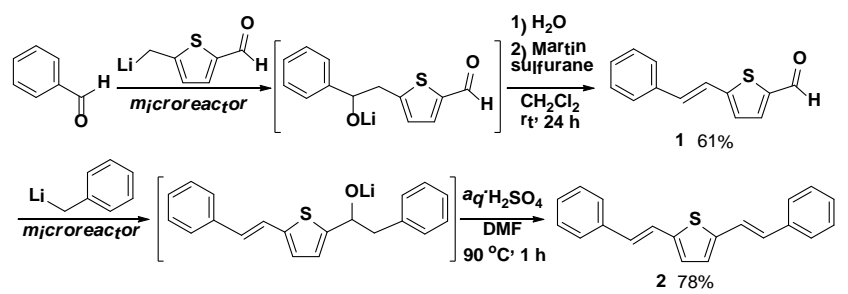

Figure 4. Synthesis of $\pi$-conjugated systems using (5formylthiophen-2-yl)methyllithium.

In conclusion, flash chemistry using flow microreactor systems enables the generation and reactions of benzyllithiums bearing aldehyde carbonyl groups. Extremely fast micromixing is responsible for the generation of benzyllithiums avoiding Wurtztype coupling, and high-resolution residence time control is responsible for survival of aldehyde carbonyl groups. The present findings open a new aspect of protecting-group-free ${ }^{[18]}$ organolithium chemistry.

\section{Experimental Section}

Typical procedure for flow microreactor system for the lithiation of electrophilic-functionalized benzyl halides with lithium naphthalenide (LiNp) followed by the reaction with electrophiles: A flow microreactor system consisting of the build-in type system in which two T-shaped micromixers (M1 and M2) and a microtube reactor (R1) were combined, a microreactor R2, and three precooling units (P1 (inner diameter $\phi=1000 \mu \mathrm{m}$, length $\mathrm{L}=300 \mathrm{~cm}$ ), P2 $(\phi=1000 \mu \mathrm{m}, \mathrm{L}=300 \mathrm{~cm})$ and $\mathrm{P} 3(\phi=1000 \mu \mathrm{m}, \mathrm{L}=300 \mathrm{~cm}))$ was used. A solution of electrophilic-functionalized benzyl halides (0.05 M in THF) was introduced to M1 by a plunger pump (15 $\mathrm{mL} / \mathrm{min})$. A solution of lithium naphthalenide (LiNp) $(0.22 \mathrm{M}$ in THF) was introduced to M1 by a micro feeder pump $(7.5 \mathrm{~mL} / \mathrm{min})$. The mixing solution was passed through $\mathrm{R} 1(\phi=250 \mu \mathrm{m}, \mathrm{L}=1.0$ $\mathrm{cm})$. The reaction mixture was mixed with a solution of electrophile $(0.20 \mathrm{M}$ in THF $)$ in $\mathrm{M} 2(\phi=250 \mu \mathrm{m})$ by a plunger pump (7.5 $\mathrm{mL} / \mathrm{min})$, and the resulting solution was passed through $\mathrm{R} 2(\phi=$ $1000 \mu \mathrm{m}, \mathrm{L}=50 \mathrm{~cm}$ ). After a steady state was reached, an aliquot of the product solution was collected and was treated with sat. aqueous $\mathrm{NH}_{4} \mathrm{Cl}$ solution. The reactions were carried out at $-78{ }^{\circ} \mathrm{C}$. Organic layer was analyzed by gas chromatography or isolated by flash chromatography or GPC.

Received: ((will be filled in by the editorial staff))

Published online on ((will be filled in by the editorial staff))

Keywords: microreactors, lithiation, carbonyl group

[1] a) R. W. Hoffmann, Synthesis 2006, 3531; b) N. A. Afagh, A. K. Yudin, Angew. Chem., Int. Ed. 2010, 49, 262.

[2] a) J. A. Bajgrowicz, A. El. Hallaoui, R. Jacquier, Ch. Pigiere, Ph. Viallefont, Tetrahedron 1985, 41, 1833; b) T. Mandai, S. Matsumoto, M. Kohama, M. Kawada, J. Tsuji, J. Org. Chem. 1990, 55, 5671; c) T. Mandai, T. Murakami, M. Kawada, J. Tsuji, Teterahedron Lett. 1991, 32, 3399; d) J. F. Gil, D. J. Ramón, M. Yus, Tetrahedron 1993, 49, 4923.

[3] a) J. E. Baldwin, R. M. Williams, Organolithiums: Selectivity for Synthesis; Pregamon: Amsterdam, 2002; b) P. Knochel, Handbook of Functionalized Organometallics; Wiley-VCH: Weinheim, 2005; c) R. Luisi, V. Capriati, Lithium Compounds in Organic Synthesis - From Fundamentals to Applications; WileyVCH: Weinheim, 2014.

[4] Flash chemistry is defined as a field of chemical synthesis where extremely fast reactions are conducted in a highly controlled manner to produce the desired compounds with high selectivity: a) J. 
Yoshida, Chem. Commun. 2005, 4509; b) J. Yoshida, A. Nagaki, T. Yamada, Chem. Eur. J. 2008, 14, 7450; c) P. J. Nieuwland, K. Koch, N. van Harskamp, R. Wehrens, J. C. M. van Hest, F. P. J. T. Rutjes, Chem. Asian J. 2010, 5, 799; d) J. Yoshida, Chem. Record 2010, 10, 332; e) J. Yoshida, Y. Takahashi, A. Nagaki, Chem. Commun. 2013, 49, 9896.

[5] Some examples of generation and reactions of short-lived organolithiums in flow: a) H. Usutani, Y. Tomida, A. Nagaki, H. Okamoto, T. Nokami, J. Yoshida, J. Am. Chem. Soc. 2007, 129, 3046; b) A. Nagaki, E. Takizawa, J. Yoshida, J. Am. Chem. Soc. 2009, 131, 1654; c) A. Nagaki, A. Kenmoku, Y. Moriwaki, A. Hayashi, J. Yoshida, Angew. Chem., Int. Ed. 2010, 49, 7543; d) Y. Tomida, A. Nagaki, J. Yoshida, J. Am. Chem. Soc. 2011, 133, 3744 e) H. Kim, A. Nagaki, J. Yoshida, Nat. Commun. 2011, 2, 264; f) A. Nagaki, C. Matsuo, S. Kim, K. Saito, A. Miyazaki, J. Yoshida, Angew. Chem., Int. Ed. 2012, 51, 3245.

[6] Books on flow microreactor synthesis: a) W. Ehrfeld, V. Hessel, H. Löwe, Microreactors; Wiley-VCH: Weinheim, 2000; b) V. Hessel, S. Hardt, H. Löwe, Chemical Micro Process Engineering; Wiely-VCH Verlag: Weinheim, 2004; c) J. Yoshida, Flash Chemistry. Fast Organic Synthesis in Microsystems; WileyBlackwell, 2008; d) V. Hessel, A. Renken, J. C. Schouten, J. Yoshida, Eds, Micro Precess Engineering; Wiley-VCH Verlag: Weinheim, 2009; e) T. Wirth, Eds, Microreactors in Organic Chemistry and Catalysis, 2nd Ed.; Wiley-VCH Verlag: Weinheim, 2013.

[7] Reviews on flow microreactor synthesis: a) K. Jähnisch, V Hessel, H. Löwe, M. Baerns, Angew. Chem., Int. Ed. 2004, 43, 406; b) G. N. Doku, W. Verboom, D. N. Reinhoudt, A. van den Berg, Tetrahedron 2005, 61, 2733; c) P. Watts, S. J. Haswell, Chem. Soc. Rev. 2005, 34, 235; d) K. Geyer, J. D. C. Codée, P. H. Seeberger, Chem. Eur. J. 2006, 12, 8434; e) A. J. deMello, Nature 2006, 442, 394; f) H. Song, D. L. Chen, R. F. Ismagilov, Angew. Chem., Int. Ed. 2006, 45, 7336; g) J. Kobayashi, Y. Mori, S. Kobayashi, Chem. Asian. J. 2006, 1, 22; h) M. Brivio, W. Verboom, D. N. Reinhoudt, Lab Chip 2006, 6, 329; i) B. P. Mason, K. E. Price, J. L. Steinbacher, A. R. Bogdan, D. T. McQuade, Chem. Rev. 2007, 107, 2300; j) B. Ahmed-Omer, J. C. Brandt, T. Wirth, Org. Biomol. Chem. 2007, 5, 733; k) P. Watts, C. Wiles, Chem. Commun. 2007, 443; l) T. Fukuyama, M. T. Rahman, M. Sato, I. Ryu, Synlett 2008, 151; m) R. L. Hartman, K. F. Jensen, Lab Chip 2009, 9, 2495; n) J. P. McMullen, K. F. Jensen, Annu. Rev. Anal. Chem. 2010, 3, 19; o) J. Yoshida, H. Kim, A. Nagaki, ChemSusChem 2011, 4, 331; p) C. Wiles, P. Watts, Green Chem. 2012, 14, 38; q) A. Kirschining, L. Kupracz, J. Hartwig, Chem. Lett. 2012, 41, 562; r) D. T. McQuade, P. H. Seeberger, J. Org. Chem. 2013, 78, 6384; s) K. S. Elvira, X. C. i Solvas, R. C. R. Wootton, A. J. deMello, Nat. Chem. 2013, 5, 905; t) J. C. Pastre, D. L. Browne, S. V. Ley, Chem. Soc. Rev. 2013, 42, 8849; u) I. R. Baxendale, J. Chem. Technol. Biotechnol. 2013, 88, 519.

[8] Some selected recent examples: a) D. Cantillo, M Baghbanzadeh, C. O. Kappe, Angew. Chem., Int. Ed. 2012, 51, 10190; b) W. Shu, S. L. Buchwald, Angew. Chem., Int. Ed. 2012, 51, 5355; c) A. Nagaki, Y. Moriwaki, J. Yoshida, Chem. Commun. 2012, 48, 11211; d) F. Lévesque, P. H. Seeberger, Angew. Chem.,
Int. Ed. 2012, 51, 1706; e) K. C. Basavaraju, S. Sharma, R. A. Maurya, D. P. Kim, Angew. Chem., Int. Ed. 2013, 52, 6735; f) C. Brancour, T. Fukuyama, Y. Mukai, T. Skrydstrup, I. Ryu, Org. Lett. 2013, 15, 2794; g) J. D. Nguyen, B. Reiß, C. Dai, C. R. J. Stephenson, Chem. Commun. 2013, 49, 4352; h) C. Battilocchio, J. M. Hawkins, S. V. Ley, Org. Lett. 2013, 15, 2278; i) A. S. Kleinke, T. F. Jamison, Org. Lett. 2013, 15, 710; j) L. Guetzoyan, N. Nikbin, I. R. Baxendale, S. V. Ley, Chem. Sci. 2013, 4, 764; k) S. Fuse, Y. Mifune, T. Takahashi, Angew. Chem., Int. Ed. 2014, 53, 851; l) Z. He, T. F. Jamison, Angew. Chem., Int. Ed. 2014, 53, 3353; m) A. Nagaki, Y. Takahashi, J. Yoshida, Chem. Eur. J. 2014, 20, 7931; n) A. Nagaki, D. Ichinari, J. Yoshida, J. Am. Chem. Soc. 2014, 136, 12245.

[9] N. Chinkov, H. Chechik, S. Majumdar, A. Liard, I. Marek, Synthesis 2002, 17, 2473.

[10] a) H. Gilman, H. McNinch, J. Org. Chem. 1961, 26, 3723; b) D. F. Hoeg, D. I. Lusk, J. Organomet. Chem. 1966, 5, 1; c) C. G. Screttas, M. Micha-Screttas, J. Org. Chem. 1979, 44, 713; d) M. Clarembeau, A. Krief, Tetrahedron Lett. 1985, 26, 1093; e) T. Hiiro, N. Kambe, A. Ogawa, N. Miyoshi, S. Murai, N. Sonoda, Angew. Chem., Int. Ed. Engl. 1987, 26, 1187; f) D. Guijarro, B. Mancheño, M. Yus, Tetrahedron 1992, 48. 4593; g) C. Strohmann, K. Lehmen, K. Wild, D. Schildbach, Organometallics 2002, 21, 3079; h) M. Casimiro, P. Oña-Burgos, J. Meyer, S. Styra, I. Kuzu, F. Breher, I. Fernández, Chem. Eur. J. 2013, 19, 691.

[11] a) K. Smith, D. Hou, J. Chem. Soc., Perkin Trans. 1995, 1, 185; b) C. Gómez, F. F. Huerta, M. Yus, Tetrahedron 1997, 53, 13897; c) C. Gómez, F. F. Huerta, M. Yus, Tetrahedron 1998, 54, 1853; d) C. Gómez, S. Ruiz, M. Yus, Tetrahedron 1999, 55, 7017; e) T. Arnauld, A. G. M. Barrett, B. T. Hopkins, Tetrahedron Lett. 2002, 43, 1081.

[12] a) E. P. William, D. J. Lawrence, A. S. Yousry, Org. Chem. 1976, 41, 7; b) M. Schlosser, S. Sven, Tetrahedron Lett. 1984, 25, 741; c) S. Warren, P. Wyatt, M. McPartlin, T. Woodroffe, Tetrahedron Lett. 1996, 37, 5609; d) D. Guijarro, M. Yus, J. Organomet. Chem. 2001, 624, 53; e) L. Kupracz, A. Kischning, Adv. Synth. Catal. 2013, 355, 3375.

[13] a) P. Rys, Acc. Chem. Res. 1976, 10, 345; b) P. Rys, Angew. Chem., Int. Ed. Engl. 1977, 12, 807.

[14] a) A. Nagaki, M. Togai, S. Suga, N. Aoki, K. Mae, J. Yoshida, J. Am. Chem. Soc. 2005, 127, 11666; b) J. Yoshida, A. Nagaki, T. Iwasaki, S. Suga, Chem. Eng. Technol. 2005, 28, 259; c) A. Nagaki, N. Takabayashi, Y. Tomida, J. Yoshida, Org. Lett. 2008, 18, 3937; d) A. Nagaki, D. Ichinari, J. Yoshida, Chem. Commun. 2013, 49, 3242.

[15] W. Ehrfeld, K. Golbig, V. Hessel, H. Löwe, T. Richter, Ind. Eng. Chem. Res. 1999, 38, 1075.

[16] T. Jing, T. Ting, C. Chia, L. Hsing, Z. Jia, T. Sheng, Synthesis 2010, 24, 4242.

[17] a) Y. He, W. Wu, G. Zhao, Y. Liu, Y. Li, Macromolecules 2008, 41, 9760; b) A. H. Younes, L. Zhang, M. W. Davidson, L. Zhu, Org. Biomol. Chem. 2010, 8, 5431; c) C. Zhang, J. Sun, R. Li, S. Sun, E. Lafalce, X. Jiang, Macromolecules 2011, 44, 6389. [18] I. S. Young, P. S. Baran, Nat. Chem. 2009, 1, 193. 


\section{Microreactors}

Aiichiro Nagaki, Yuta Tsuchihashi, Suguru Haraki, and Jun-ichi Yoshida*

Benzyllithiums Bearing Aldehyde Carbonyl Groups. A Flash Chemistry Approach
Reductive lithiation of benzyl halides bearing aldehyde carbonyl groups followed by the reaction with subsequently added electrophiles was successfully accomplished without affecting the carbonyl groups by taking advantage of short residence times in flow microreactors.

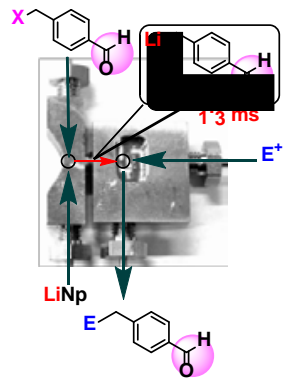

